\title{
Identificação de impactos ambientais provocados pelo lançamento de resíduos sólidos e líquidos no Rio Itapecuru
}

Neste estudo, analisou-se a problemática ambiental identificando os principais impactos ocasionados pelo lixo lançado no rio Itapecuru, o que contribui para o comprometimento da qualidade da água do corpo hídrico em questão. As principais atividades e processos responsáveis pela degradação ambiental do rio estão relacionados com a disposição inadequada do lixo e com o lançamento de dejetos por meio de esgotos não tratados. Foram realizadas pesquisas bibliográficas atividades de campo, e registros fotográficos. Os resultados apontaram que na área avaliada o esgoto doméstico oriundo das residências dos moradores, próximos das margens do rio, é jogado diretamente no corpo hídrico sem tratamento prévio, o que pode ocasionar vários problemas, tais como: poluição, desequilíbrio do ecossistema aquático, além do odor desagradável. Observou-se que as intervenções dos setores públicos na situação encontrada são mínimas, a população fica incomodada com poluição tanto visual quanto hídrica, porém não possuem meios para um descarte adequado do lixo e optam por descartá-lo da maneira mais acessível. Além de desconhecerem as leis de proteção ao meio ambiente, os residentes próximos as margens dos rios possuem pouco conhecimento quanto ao saneamento básico e um dos principais motivos para degradação está associado à ocupação e ao uso do solo urbano pelo homem. Sendo assim, conclui-se que nas proximidades do rio Itapecuru existem impactos ambientais causados pela ação do homem e são vários fatores que colaboram com a degradação do meio aquático, incluindo o lançamento de lixo.

Palavras-chave: Rio Itapecuru; Impactos Ambientais; Educação ambiental.

\section{Identification of environmental impacts caused by release of waste in the Itapecuru River}

\begin{abstract}
In this study, we analyzed the environmental problem identifying the main impacts caused by garbage released on the Itapecuru River, which contributes to the impairment of water quality of the water body in question. The main activities and processes responsible for the environmental degradation of the river are related to the inadequate disposal of garbage and the launch of waste through untreated sewage. Bibliographic research, field activities, and photographic records were carried out. The results showed that in the area evaluated the domestic sewage from the residents' residences, near the banks of the river, is thrown directly into the water body without previous treatment, which can cause several problems, such as: pollution, imbalance of the aquatic ecosystem, in addition to unpleasant odor, it was observed that the interventions of public sectors in the situation found are minimal, the population is bothered by both visual and water pollution, but do not have the means for a disposal of garbage and choose to discard them in the most accessible. Way besides not knowing environmental protection laws, residents close to the banks of rivers have little knowledge about basic sanitation and one of the main reasons for degradation is associated with the occupation and use of urban soil by man. Thus, it is concluded that in the vicinity of the Itapecuru River there are environmental impacts caused by the action of man and are several factors that contribute to the degradation of the aquatic environment, including the launch of garbage.
\end{abstract}

Keywords: Itapecuru River; Environmental Impacts; Environmental Education.

Topic: Desenvolvimento, Sustentabilidade e Meio Ambiente

Reviewed anonymously in the process of blind peer.

Cristina da Silva Pereira

Instituto Federal do Maranhão, Brasil

http://lattes.cnpq.br/5565239650562928

http://orcid.org/0000-0002-5311-1658

cristinasilper2016@gmail.com

Mayara Oliveira Sousa Rodrigues (iD)

Instituto Federal do Maranhão, Brasil

http://lattes.cnpq.br/6353979902086980

http://orcid.org/0000-0001-9558-6224

mayara.oliveira@ifma.edu.br

Cindhi Lorrane dos Santos Barros (iD

Instituto Federal do Maranhão, Brasil

http://lattes.cnpq.br/0105247551837042

http://orcid.org/0000-0002-0645-2724

cindhy.lourrane6@gmail.com

d

DOI: 10.6008/CBPC2318-2881.2020.002.0006
Received: 09/03/2020

Approved: 10/04/2020
Bruna Lays Nascimento de Almeida

Instituto Federal do Maranhão, Brasil

http://lattes.cnpq.br/7792990505289914

http://orcid.org/0000-0002-5156-1022

brunalays2008@gmail.com

Maria Lays Sousa de Andrade Diogo

Instituto Federal do Maranhão, Brasil

http://lattes.cnpq.br/2195535423218462

http://orcid.org/0000-0001-8960-5409

laysandrade769@gmail.com
Referencing this:

PEREIRA, C. S.; RODRIGUES, M. O. S.; BARROS, C. L. S.; ALMEIDA, B. L. N.; DIOGO, M. L. S. A.. Identificação de impactos ambientais provocados pelo lançamento de resíduos sólidos e líquidos no Rio Itapecuru. Nature and Conservation, v.13, n.2, p.58-66, 2020. DOI: http://doi.org/10.6008/CBPC2318-2881.2020.002.0006 


\section{INTRODUÇÃO}

A água representa, sobretudo, o principal constituinte de todos os organismos vivos. Os ambientes aquáticos são utilizados em todo o mundo com distintas finalidades, entre as quais se destacam o abastecimento de água, a geração de energia, a irrigação, a navegação, a aquicultura e a harmonia paisagística (MORAES et al., 2002).

Sabe-se que apesar da abundância de água no planeta, apenas uma pequena parcela é própria para o consumo e por ser um recurso finito, deve ser preservado (SILVA, 2015). O crescimento populacional, aliado à crescente demanda por recursos naturais, tem sido responsável por diversos impactos ambientais identificados em corpos hídricos. Dentre os impactos observados se destacam o descarte inadequado de lixo e de esgoto não tratados em rios, o que tem contribuído para o desequilíbrio desse tipo de ecossistema.

Nas últimas décadas, os ecossistemas aquáticos têm sido alterados de maneira significativa em função de diversos impactos ambientas oriundos de atividades antrópicas, tais como: mineração, construção de barragens e represas, desvio do curso natural de rios, lançamento de efluentes domésticos e industriais não tratados, desmatamento da mata ciliar, superexploração de recurso pesqueiro, introdução de espécies exóticas, entre outros.

O desmatamento e a poluição dos mananciais se apresentam como um agravante no processo de degradação dos recursos hídricos pois acontecem de maneira crescente em todas as regiões do país. Realidade essa que acaba por comprometer a qualidade da água e da possibilidade de aproveitamento da mesma para suprir as necessidades vitais não só humanas (RAMOS et al., 2009). Isso quando não acaba por poluir o solo e a água subterrânea, que acaba sendo necessária a avaliação e identificação dos impactos ambientais ocasionados pelos usos múltiplos dos corpos hídricos, bem como, a necessidade de medidas de mitigação e sustentabilidade, para que esse ecossistema e as características da água possam ser mantidos em equilíbrio e com qualidade, respectivamente.

A bacia hidrográfica do rio Itapecuru é a segunda maior bacia genuinamente maranhense. No passado, muitos engenheiros, usinas e indústrias de beneficiamento de algodão prosperaram na região. $O$ rio proporcionou, também, o estabelecimento de uma rota importante de penetração para o interior do Estado, permitindo a expansão da produção agrícola. Atualmente, em toda a sua extensão, observam-se várias evidências de degradação ambiental, fato que vem comprometendo as potencialidades naturais da área. $\mathrm{O}$ atual estado de degradação ambiental da área da bacia do rio Itapecuru salienta a necessidade de estudos ambientais que indiquem medidas concretas para a sua recuperação (FEITOSA et al., 2002).

Dessa forma, este trabalho foi proposto com o objetivo de identificar os principais impactos ambientais, resultantes da degradação ambiental humana, no trecho urbano do rio Itapecuru, localizado no município de Codó/MA. O rio, em seu trecho codoense, é utilizado principalmente para pesca, recreação, lavagem de couro bovino, irrigação de hortas comunitárias e abastecimento de criatórios de peixes. 


\section{METODOLOGIA}

O trabalho foi realizado a partir da coleta de dados in loco, no município de Codó - MA no perímetro urbano do rio Itapecuru além da pesquisa bibliográfica realizada durante todo o desenvolvimento das atividades relativas ao tema proposto. Foram realizadas atividades de campo e registros fotográficos nas margens do rio Itapecuru.

Paralelamente as pesquisas bibliográficas, que envolveram a leitura, análise e discussão de trabalhos científicos sobre o tema proposto, dados sobre o lançamento de lixo e esgoto in natura no rio foram identificados, a partir de observações.

\section{RESULTADOS E DISCUSSÃO}

Dentre os impactos ambientais identificados, a partir da metodologia proposta, destacam-se o lançamento de lixo doméstico e de esgotos não tratados diretamente no rio Itapecuru. O lixo ocupa atualmente o local que outrora pertencia à mata ciliar, que foi removida das margens do rio em grande parte do seu curso, principalmente em seu perímetro urbano.

No que diz respeito ao lançamento de resíduos sólidos se observou que, no período chuvoso (época das cheias), devido à maior velocidade da correnteza da água no ambiente lótico, o rio arrasta e espalha os mais variados tipos de resíduos, em maior quantidade os plásticos (Figuras 1 e 2), com o predomínio de sacos e sacolas de plástico, que ficam retidos na margem ou são depositados no canal fluvial, contribuindo para o assoreamento, que também foi notado no local. Além disso, verificou-se ainda a prática de lançar animais mortos no leito do rio. É importante ressaltar a carência no serviço de coleta, transporte, tratamento e disposição dos resíduos sólidos da região, o que contribui para que a população descarte a parte não coletada do lixo nas margens do corpo hídrico.

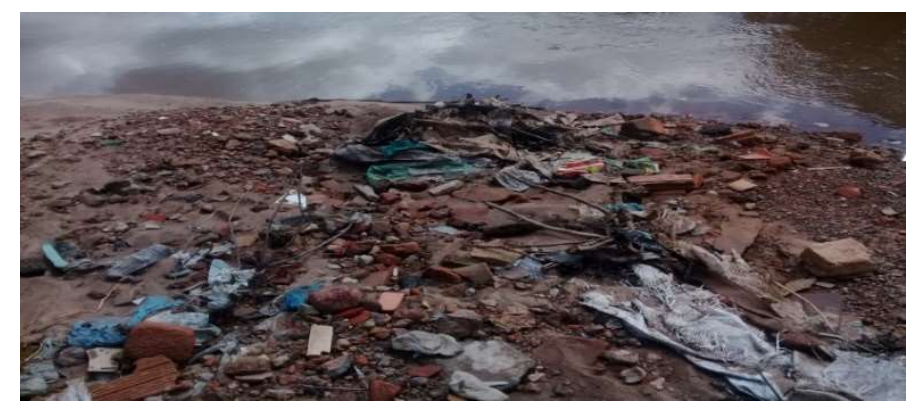

Figura 1: Lixo lançado às margens do rio Itapecuru.

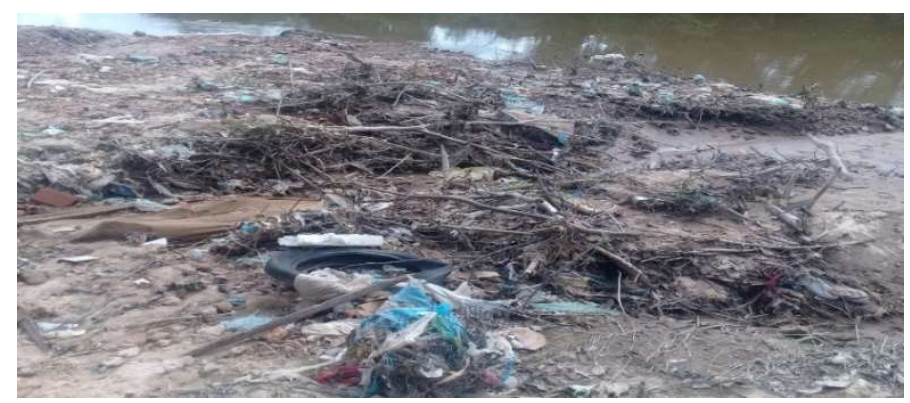

Figura 2: Sacolas e pneus lançados às margens do rio Itapecuru. 
Diversos trabalhos realizados em outros municípios maranhenses, por onde correm as águas do rio Itapecuru, apontam que o lançamento de lixo e de resíduos líquidos in natura, depositados inadequadamente em suas margens, são responsáveis pela degradação identificada no corpo hídrico em estudo (SILVA et al., 2005; SILVA et al., 2011; CANTANHEDE et al., 2015; SENA, 2017). Esses impactos podem interferir na qualidade da água do rio (CANTANHEDE et al., 2015; COSTA et al., 2015).

O rio Itapecuru atua como corpo hídrico receptor de esgoto lançado sem tratamento prévio (Figura 3), o que pode ocasionar vários problemas, principalmente no que diz respeito à poluição, consequente desequilíbrio do ecossistema, além do odor desagradável na região. Acredita-se que a degradação ambiental identificada pode estar associada à ocupação e ao uso do solo urbano pelo homem. Ocupação realizada de forma acelerada, desorganizada e que não leva em consideração a importância da preservação do meio ambiente, o que inclui a preservação do rio.

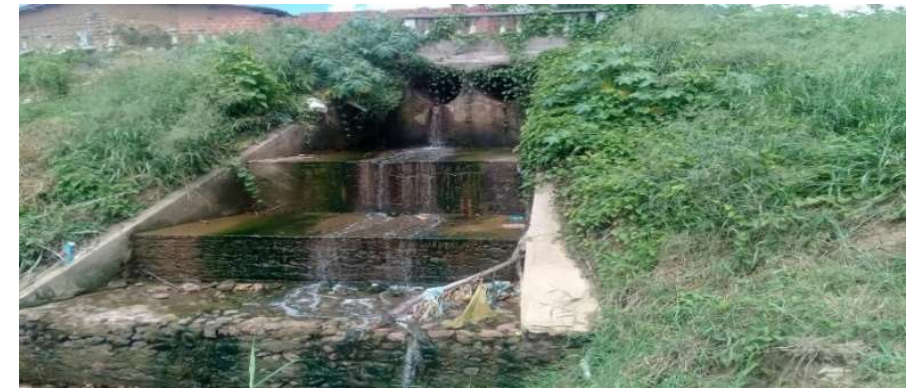

Figura 3: Tubulações de esgoto in natura lançado diretamente no rio Itapecuru.

O município não possui um sistema de coleta de esgoto integral, ficando a coleta restrita a algumas regiões da cidade. Os dejetos coletados ficam armazenados, sem tratamento, em lagoas artificiais de estabilização localizadas próximas ao rio Itapecuru. Esse sistema de coleta recebe uma pequena parcela do esgoto doméstico de todo o município e dos resíduos provenientes de matadouros.

Nos ecossistemas aquáticos, o que inclui os rios, lagos e córregos, acredita-se que a maior representatividade, tanto no que diz respeito ao volume quanto a carga, é de origem orgânica, principalmente porque a matéria orgânica está associada aos componentes presentes nos esgotos domésticos (FREITAS et al., 2016). O tratamento prévio do esgoto antes do seu lançamento no rio pode reduzir a carga de poluição, consequentemente, pode melhorar a qualidade da água (LEE et al., 2017).

Estudos recentes demonstram que a emissão de gases de efeito estufa nos rios não está relacionada somente com a atividade de micro-organismos e com o sedimento, mas também, relaciona-se com a descarga de águas residuais provenientes de atividades agrícolas e industriais e do esgoto doméstico, lançados nos rios e ricos em nutrientes, tais como, nitrogênio ( $N$ ) e fósforo $(P)$. Observou-se que as atividades humanas estão alterando os ciclos biogeoquímicos de compostos, tais como, o carbono e o nitrogênio nos rios (HU et al., 2018).

No que diz respeito à percepção ambiental dos moradores da região ribeirinha, observou-se que os residentes locais ficam incomodados com o mau cheiro oriundo do lançamento de esgotos e com a poluição visual resultante do despejo de lixo doméstico às margens do rio, mas acreditam que os principais 
responsáveis pela degradação ambiental e pela mitigação dos impactos ambientais são as entidades públicas, uma vez que, equilíbrio e preservação ambiental exigem planejamento urbano, programas regulares de conscientização ambiental, além do cumprimento às leis ambientais de proteção ao meio ambiente.

Além dos impactos ambientais mencionados acima, pode-se destacar ainda a supressão da mata ciliar, a introdução de espécies vegetais exóticas, e a ocupação do solo como impactos importantes, que já foram identificados em outros estudos ambientais realizados em corpos hídricos (MELO et al., 2013) e durante o período chuvoso, pode-se observar o aumento na proliferação de doenças na população humana, como por exemplo, o aumento nos casos de amebíase, hepatite A e leptospirose (FREITAS et al., 2016).

O uso e ocupação do solo nas proximidades do rio Itapecuru contribuem com a poluição da área, uma vez que, o lançamento de resíduos sólidos e líquidos sem tratamento, além das construções em áreas próximas às margens do rio, está entre as atividades praticadas pelo homem e que contribuem com a intensificação da poluição, como já foi mencionado (SENA, 2017).

A realidade apresentada na região pode ser observada em vários outros municípios do país sendo perceptível a disposição incorreta de resíduos, que são lançados diretamente em corpos hídricos, e a parte lixiviada dessa massa de resíduos acaba sendo disposta no solo contaminando os cursos d'água, acarretando vários problemas, como o aumento da demanda bioquímica de oxigênio (DBO), diminuição dos níveis de oxigênio dissolvido, formação de correntes ácidas, carga elevada de sedimentos, presença de coliformes acima do aceitável, aumento da turbidez, intoxicação de organismos presentes naquele ecossistema, incluindo o homem, quando este utiliza água contaminada para consumo (MARQUES, 2011).

O quantitativo de pessoas residindo em determinadas regiões, como em áreas metropolitanas deve ser levada em consideração para uma gestão integrada de recursos hídricos, contudo, a população necessita cada vez mais de água, tanto para abastecimento público, quanto para dissolução das cargas poluidoras urbanas. A poluição hídrica no país tem-se agravado constantemente sem que ocorra uma intervenção significativa, sendo crescente o manejo inadequado do solo, erosão e desmatamento. Esses fatores, associados à distribuição anual de chuvas e às características climáticas, levam a danos ambientais, entre os quais se destacam o aumento do transporte de sedimento e a contaminação orgânica e química das águas. (SANTOS et al., 2005).

O Brasil por ser abundante em rios, em todo o território, faz com que a população tenha a ilusão de que os recursos hídricos são inesgotáveis, não percebendo que todos os dias são despejadas quantidades expressivas de resíduos nos corpos hídricos do território. Esses resíduos prejudicam a qualidade da água, provoca processos erosivos que levam à consequente diminuição no volume de água nos corpos hídricos. $O$ lixo causa vários problemas, contudo a poluição da água é o principal, representando que um ou mais de seus usos foram prejudicados, atingindo diretamente a sociedade humana, pois a água é um elemento essencial utilizada para diversos fins, como alimento, para tomar banho, para lavar roupas e utensílios, além de ser fonte principal para dessedentação dos animais domésticos (ANDRADE et al., 2009).

De acordo com Tucci et al. (2001), a falta de tratamento de esgotos é um agravante dos impactos ambientais da maioria das cidades, por não possuírem um tratamento de esgoto adequado acabam lançando 
os esgotos na rede de esgotamento pluvial de forma clandestina, e estes, acabam escoando para os rios. Essas condições ambientais inadequadas, acabam reduzindo as condições da saúde pública e a qualidade de vida da população, na mesma proporção que aumentam os riscos de impactos ambientais.

A produção excessiva de resíduos tanto sólidos quanto líquidos pela população juntamente com a gestão inadequada gera impactos ambientais graves, provoca doenças, assoreamento dos rios e córregos, entupimento de bueiros, contaminação do ar, entre outros. A falta de conscientização da população quanto a dar uma destinação correta a esses resíduos consiste em um problema para um gerenciamento eficiente. Neste aspecto, a Educação Ambiental torna-se fundamental para um melhor manejo desses resíduos e com isso, a redução dos danos ambientais (GUSMÃO, 2000, citado por ROCHA et al., 2012).

A educação ambiental se faz necessária pois a participação da população é de suma importância na preservação dos recursos naturais pois, a população local pode atuar com mais eficiência na 'fiscalização' do que o Estado no cumprimento de um determinado acordo e no controle do uso de bens públicos ou dos recursos naturais. As soluções para questões que envolvem desenvolvimento e conservação/preservação também envolve a sociedade civil e o coletivo, pois muitas vezes, os residentes de um determinado local são, ao mesmo tempo, causadores e vítimas de parte dos problemas ambientais (MARCATTO, 2002).

Os impactos socioambientais acontecem pela falta de investimentos nos sistemas de esgotamento sanitário e de estações de tratamento. Com o pouco investimento no tratamento de esgotos, a população procura por outras alternativas, tais como, os despejos dos esgotos são conectados à rede pluvial por meio de ligações clandestinas, o que acaba transportando uma grande quantidade de poluentes aos corpos hídricos receptores (TUCCI, 2005).

A crescente geração de resíduos sólidos urbanos (RSU) é problema em todo o mundo e tem se tornado assunto de grande preocupação, particularmente em todos os centros urbanos. A gestão dos RSU é considerada uma das mais desafiadoras enfrentadas em grande parte dos países em desenvolvimento que sofrem devido aos problemas da poluição causados pelas grandes quantidades de RSU (AL-KHATIB et al., 2010).

Percebendo-se os altos níveis de poluição e degradação dos leitos dos rios e que a água potável é um recurso finito procurou-se preservá-la com a criação de algumas leis, pois a água, independentemente do reconhecimento jurídico, é um bem de valor ambiental, cujo valor econômico passou a ser reconhecido pelo ordenamento jurídico brasileiro, com o advento da Lei no 9.433/97, que criou a Política Nacional de Recursos Hídricos (PNRH) e instituiu o Sistema Nacional de Gerenciamento de Recursos Hídricos e regulamentou o inciso XIX do art. 21 "que aborda a instituição do sistema nacional de gerenciamento de recursos hídricos e define critérios de outorga de direitos de seu uso" da Constituição Federal (FERREIRA, 2008).

A Constituição Federal dedicou um capítulo à proteção ambiental, garantindo o direito de todos ao meio ambiente ecologicamente equilibrado e essencial à sadia qualidade de vida. Os recursos hídricos, além de estarem inseridos nos textos legais mencionados, possuem proteção específica através da Política Nacional de Recursos Hídricos, Lei 9.433/97, a qual traz em seu artigo 1ํ, inciso VI, que 'a gestão dos recursos hídricos deve sempre proporcionar o uso múltiplo das águas', além de outros fundamentos não menos 
importantes que a gestão dos recursos hídricos. Deve haver uma descentralização e ter a participação do Poder Público, da sociedade e usuários (RAMOS et al., 2009).

Para ampliar a área de atuação com relação à proteção do meio ambiente, a Constituição Federal de 1988 determinou o regime de competências legislativas e administrativas dos três níveis de governo. A proteção ao meio ambiente como um todo e, em particular, o controle da poluição foram inseridos os objetivos comuns ou concernentes a União, Estados e municípios. É papel dos municípios a elaboração, aprovação e fiscalização de instrumentos relacionados com o ordenamento territorial, dentre eles, os planos diretores, o zoneamento, o parcelamento do solo e o desenvolvimento de programas habitacionais; a delimitação de zonas industriais, urbanas e de preservação ambiental, os planos e sistemas de transporte urbanos, entre outras atividades com impacto nos recursos hídricos, sobretudo em bacias hidrográficas localizadas em áreas predominantemente urbanas (CARNEIRO et al., 2008).

\section{CONCLUSÕES}

O presente estudo mostrou que nas proximidades do rio existem impactos ambientais causados pela ação do homem, tais como: esgoto doméstico, lixo, garrafas pet, lixo eletrônico, etc. São vários fatores que ajudam na degradação do meio aquático. Em visita ao local, foram identificados vários problemas, tais como: desmatamento da mata ciliar, processos erosivos e lixo acumulado. O lixo também pode gerar chorume e contaminar a água e o solo. Ainda pode servir de alimento para animais e insetos que são vetores de doenças.

Com o lançamento do esgoto doméstico, há um aumento da matéria orgânica na água, o que faz com que o equilíbrio local seja afetado. Esse processo é conhecido como eutrofização, podendo levar ao surgimento de microalgas, sufocamento de peixes e transmissão de doenças causadas pelas fezes humanas para outros consumidores da água, além de possivelmente, o rio estar contaminado com substâncias tóxicas.

Sugere-se que sejam tomadas medidas mitigadoras para amenizar os impactos e até mesmo solucionar tais problemas, como elaborar trabalhos de percepção ambiental, o que poderia contribuir para a minimização da quantidade de lixo atualmente presente nas margens do rio. Existe uma falta de consciência sobre as consequências futuras causadas pela quantidade de objetos lançados as margens do rio.

Os poderes públicos juntamente com a população poderiam efetuar uma campanha de monitoramento para amenizar os problemas existentes e assim evitar novos problemas em caso de enchentes. Como sugestões para a melhoria da qualidade ambiental do rio Itapecuru na área estudada, citam-se a limpeza, a fiscalização, conscientização dos usuários, o saneamento básico, e a recuperação local.

A população deve atuar em conjunto com a gestão pública para solucionar o problema apresentado em questão, pois a população local é a maior interessada em acabar com o mal cheiro, a poluição visual, o risco de inundações e possível escassez de tal recurso. O município precisa aplicar as leis que regem a proteção do meio ambiente procurando minimizar os impactos gerados nas margens dos rios e a poluição dos recursos hídricos, contudo, o Brasil possui várias leis de proteção ao meio ambiente que não são aplicadas e se aplicadas, não são suficientes para reduzir os altos índices de poluição apresentados em todo o país. Leis essas que visam a conservação e preservação do ambiente para as gerações futuras se executadas de forma 
correta.

A preocupação com a degradação ambiental é de longa data e deve permanecer. Todavia, a situação não reverteu e sim se agravou com o aumento da população, mesmo com leis de proteção ao ambiente, as margens de rios ainda estão sendo comprometidas pois não são respeitados os espaçamentos mínimos para ocupação das residências próximo as margens dos rios, o desmatamentos também é frequente, contribuindo para o assoreamento, o tratamento de esgotos não só no município como no país inteiro não é eficiente, a carga de resíduos depositados nos corpos hídricos é maior que a tratada.

Dessa forma, é necessário buscar alternativas que envolvam a participação da população, aguçando a sua percepção sobre a importância e a necessidade da preservação, a fim de garantir juntamente ao poder público, a execução de políticas públicas capazes de garantir a minimização dos impactos ambientais acima descritos e a sustentabilidade necessária para as atuais e futuras gerações.

\section{REFERÊNCIAS}

AL-KHATIB, I.; MONOU, M.; ZAHRA, A. S. F. A.; SHAHEEN, H. Q.; KASSINOS, D.. Caracterização de resíduos sólidos, quantificação e práticas de gestão em países em desenvolvimento. Um estudo de caso: distrito de Nablus Palestina. Revista de Gestão Ambiental, v.91, n.5, p.1131$1138,2010$.

ANDRADE, A. R.; FELCHAK, I. M.. A poluição urbana e o impacto na qualidade da água do Rio das AntasIrati/PR. Geoambiente, n.12, p.01-25, 2009.

BRASIL. Lei n. 9.433, de 8 de janeiro de 1997. Institui a Política Nacional de Recursos Hídricos, cria o Sistema Nacional de Gerenciamento de Recursos Hídricos, regulamenta o inciso XIX do art. 21 da Constituição Federal, e altera o art. 10 da Lei no 8.001, de 13 de março de 1990, que modificou a Lei no 7.990, de 28 de dezembro de 1989. Brasília: DOE, 1997.

BRASIL. Constituição 1988 Constituição da República Federativa do Brasil: texto constitucional promulgado em 5 de outubro de 1988 , com as alterações determinadas pelas Emendas Constitucionais de Revisão nos 1 a 6/94, pelas Emendas Constitucionais nos 1/92 a 91/2016 e pelo Decreto Legislativo no 186/2008. Brasília: DOE, 1988.

CANTANHEDE, E. K. P.; AGUIAR, A. D. M.; SOBRINHO, O. P. L.; MORAES, P. S. S.; OLIVEIRA, L. S.; XAVIER, R. S.; PEREIRA, A. I. S.. Análise microbiológica das águas do rio Itapecuru no município de Codó (MA), Brasil. Revista Ibero-Americana de Ciências Ambientais, v.6, n.1, p.7-13, 2015.

CARNEIRO, P. R. F.; CARDOSO, A. L.; AZEVEDO, J. P. S.. O planejamento do uso do solo urbano e a gestão de bacias hidrográficas: o caso da bacia dos rios Iguaçu/Sarapuí na Baixada Fluminense. Cadernos Metrópole., n.19, 2008.

COSTA, C. F.; AZEVEDO, C. A. D.; FERREIRA, S. S.; MOURA, E. P. S.. Análise microbiológica da água do rio Itapecuru em Caxias, MA, Brasil. Revista Interface, n.10, p.274-283, 2015.

FEITOSA, A. C.; ALMEIDA, E. P.. A degradação ambiental do Rio Itapecuru na sede do município de Codó/MA. Cad. Pesq., São Luís, v.13, n.1, p.31-45, 2002.
FERREIRA, A. M. M.; NASCIMENTO, L. M.. Desenvolvimento e políticas públicas na constituição brasileira de 1988: a questão das águas. In: CONGRESSO NACIONAL DO CONPED, 17. Anais. Brasília, 2008.

FREITAS, L. S.; SILVA, J. C.; OLIVEIRA, R. S.. A falta de saneamento e o impacto ambiental em rios urbanos. In: ENCONTRO LATINO AMERICANO DE INICIAÇÃO CIENTÍFICA, 20. Anais. São José dos Campos, 2016. p.1-6.

HU, B.; WANG, D.; ZHOU, J.; MENG, W.; LI, C.; SUN, Z.; GUO X.; WANG, Z.. Greenhouse gases emission from these wage drain in grivers. Science of The Total Environmental, v.612, p.1454-1462, 2018.

LEE, I.; HWANGB, H.; LEEC, J.; YUB, N.; YUNB, J.; KIMA, H.. Modeling approach evaluation of environmental impacts on river water quality: A case study with Galing River, Kuantan, Pahang, Malaysia. Ecological Modelling, v.353, p.167-173, 2017.

MARCATTO, C.. Educação ambiental: conceitos e princípios. Belo Horizonte: FEAM, 2002.

MELO, J. M. M.; LOPES, I.; GUIRRA, I. C.; AMORIM, M. C. C.. Diagnóstico dos impactos ambientais provocados pelo desenvolvimento urbano sobre as margens do rio São Francisco, um estudo de caso da cidade de Santa Maria da Boa Vista/PE. In: CONGRESSO BRASILEIRO DE GESTÃO AMBIENTAL, 4. Anais. Salvador, 2013. p.1-6.

MORAES, D. S. L.; JORDÃO, B. Q.. Degradação de recursos hídricos e seus efeitos sobre a saúde humana. Rev. Saúde Pública, v.36, n.3, p.370-374, 2002.

RAMOS, A. M. T.; SPARENBERGER, R. F. L.. A política nacional de recursos hídricos e o efeito bumerangue da sociedade de risco. Revista da Faculdade de Direito da UFG, v.33, n.2, p.169-183, 2009.

ROCHA, M. B.; SANTOS, N. P.; NAVARRO, S. S.. Educação ambiental na gestão de resíduos sólidos: concepções e práticas de estudantes do Curso Superior de Tecnologia em 
Gestão Ambiental. Revista de Educação Ambiental, v.17, n.1, p.99-122, 2012.

SANTOS, D. G.; ROMANO, P. A.. Conservação da água e do solo, e gestão integrada dos recursos hídricos. Revista de Política Agrícola, v.14, n.2, p.51-64, 2005.

SENA, F. M. S.. Convivendo às margens do rio Itapecuru: um estudo de caso sobre os impactos ambientais em Codó, Maranhão. Monografia (Bacharelado em Licenciatura Plena em Biologia) - Instituto Federal de Educação, Ciência e Tecnologia do Maranhão, Codó, 2017.

SILVA, D. J.; CONCEIÇÃO, G. M.. Rio Itapecuru: Caracterização Geoambiental e Socioambiental, Município de Caxias, Maranhão, Brasil. Scientia Plena, v.7, n.1, p.1-26, 2011.
SILVA, R. N. M.; GOMES, L. V.; FREITAS, M. I. C.; GEDEON, A D.; DUARTE, M. C. R.. Percepção ambiental do rio Itapecuru nas cidades de Pirapemas, Cantanhede, Itapecuru Mirim, Bacabeira, Santa Rita e Rosário. In: CONGRESSO BRASILEIRO DE ENGENHARIA SANITÁRIA E AMBIENTAL, 23. Anais. Campo Grande, 2005.

SILVA, H. J. B.; MENDES, W. L. T.; MOURA, K. C.; MAGALHÃES, L. W. G.; COSTA, M. S. V.. A importância do enquadramento do rio Itapecuru e a qualidade da água distribuída em Caxias/MA. In: CONGRESSO TÉCNICO CIENTÍFICO DA ENGENHARIA E DA AGRONOMIA. Anais. Fortaleza: CONTECC, 2015

TUCCI, C. E. M.; HESPANHOL, I.; CORDEIRO NETTO, O. M.. Gestão da água no Brasil. Brasília: UNESCO, 2001.

TUCCI, C. E. M.. Gestão de Águas Pluviais Urbanas. Unesco, 2005.

A CBPC - Companhia Brasileira de Produção Científica (CNPJ: 11.221.422/0001-03) detém os direitos materiais desta publicação. Os direitos referem-se à publicação do trabalho em qualquer parte do mundo, incluindo os direitos às renovações, expansões e disseminações da contribuição, bem como outros direitos subsidiários. Todos os trabalhos publicados eletronicamente poderão posteriormente ser publicados em coletâneas impressas sob coordenação da Sustenere Publishing, da Companhia Brasileira de Produção Científica e seus parceiros autorizados. Os (as) autores (as) preservam os direitos autorais, mas não têm permissão para a publicação da contribuição em outro meio, impresso ou digital, em português ou em tradução. 